\title{
Characteristics and correlates of alcohol consumption among adult chronic care patients in North West Province, South Africa
}

\author{
A Bhana, ${ }^{1,2} \mathrm{MA}, \mathrm{PhD}$; S D Rathod, ${ }^{3} \mathrm{MSc}, \mathrm{PhD}$; O Selohilwe, ${ }^{2} \mathrm{MA}$; T Kathree, ${ }^{2} \mathrm{MA}$; I Petersen, ${ }^{2} \mathrm{MSc}, \mathrm{PhD}$ \\ ${ }^{1}$ Health Systems Research Unit, South African Medical Research Council, Durban, South Africa \\ ${ }^{2}$ Centre for Rural Health, School of Nursing and Public Health, University of KwaZulu-Natal, Durban, South Africa \\ ${ }^{3}$ Department of Population Health, Faculty of Epidemiology and Population Health, London School of Hygiene and Tropical Medicine, UK
}

Corresponding author: A Bhana (arvin.bhana@mrc.ac.za)

\begin{abstract}
Background. Alcohol consumption patterns in South Africa (SA) tend to be characterised by risky patterns of drinking. Taken together with the large burden of disease associated with HIV and tuberculosis (TB), heavy alcohol consumption patterns with these chronic conditions has the potential to compromise the efficacy of treatment efforts among such patients.

Objective. To explore the characteristics, correlates and diagnoses of alcohol use disorders among chronic care patients in SA.

Method. A cross-sectional survey was conducted in three public health clinic facilities in the North West Province of SA. A total of 1322 patients were recruited from non-emergency waiting areas.

Results. Proportions of patients with abstinence, hazardous, harmful and dependent consumption were determined using logistic regression. Of the patients screened, nearly half (45\%) drank alcohol and, of these, $10 \%$ were classified as hazardous drinkers, $1.7 \%$ as harmful drinkers, and $1.6 \%$ as dependent drinkers (overall 3\% alcohol use disorder). Abstinence proportions were $60 \%$ and $38 \%$ among women and men, respectively. Alcohol Use Disorders Identification Test scores for men were $63 \%$ higher than for women. The lowest patient abstinence proportion (47\%) and highest dependent drinking (10\%) was for TB. The highest abstinence proportion was for diabetes (65\%), and the highest hazardous and harmful drinking was among TB (14\%) and HIV (7\%) patients.

Conclusions. The high levels of risky drinking among chronic care patients, particularly among patients receiving treatment for HIV and $\mathrm{TB}$, are concerning. Instituting appropriate screening measures and referral to treatment would be an important first step in mitigating the effects of risky alcohol use among chronic care patients.
\end{abstract}

S Afr Med J 2017;107(7):636-642. DOI:10.7196/SAMJ.2017.v107i7.12131

A variety of chronic and acute health conditions and injuries are affected by alcohol use, which has a major impact on disease burden. ${ }^{[1]}$ The World Health Organization (WHO) Global Status Report on Alcohol and Health 2014 indicates that in 2012, 5.1\% of the global burden of disease and injury was assigned to alcohol as was $5.9 \%$ of all global deaths. ${ }^{[2]}$ In South Africa (SA), a systematic review modelled on the SA Burden of Disease study noted that alcohol accounted for $7.1 \%$ of all deaths in SA in 2000 and the rate was particularly high among men. ${ }^{[3]}$ Interpersonal violence, at 39\%, was the top ranked for alcohol-attributable disability adjusted life years (DALYs), followed by neuropsychiatric conditions (18.4\%) and road traffic injuries (14.3\%). Alcohol also accounted for $42.8 \%$ of injury DALYs in males and $25.9 \%$ in females. ${ }^{[4]}$

While SA has high rates of alcohol abstinence ( $44 \%$ of males and $74 \%$ of females abstained from drinking over the past 12 months $s^{[2]}$, the amount of alcohol consumption per person climbs to among the highest in the world among those who drink. Against a worldwide alcohol consumption in 2010 of $6.2 \mathrm{~L}$ of pure alcohol consumed per person aged $\geq 15$ years per annum, SA recorded an average of $27.1 \mathrm{~L} /$ year, while the WHO African region recorded an average of $6.0 \mathrm{~L} /$ year. ${ }^{[2]} \mathrm{A}$ number of population-based surveys in SA indicate that a significant proportion of men and women engage in risky patterns of drinking, confirming that those who consume alcohol do so at hazardous levels. ${ }^{[4,5-8]}$ In reflecting on the priorities for research on alcohol, the International Study on Alcohol and Infectious Diseases included the need to obtain baseline information among HIV and tuberculosis (TB) populations on patterns of drinking, in addition to a need for randomised controlled trials on interventions and adherence to treatment. ${ }^{[9]}$

SA has the largest burden of HIV-infected individuals in Africa and a three-fold increase in TB over the last 10 years, the incidence of which is approaching 1000 cases per 100000 population and which is a leading cause of death. ${ }^{[10]}$ In the context of a high disease burden associated with HIV and TB in SA, heavy alcohol consumption was found to have a negative effect on CD4 cell count in HIV-infected individuals not receiving antiretroviral treatment (ART), as well as having negative effects on ART adherence among those who were on treatment. ${ }^{[11]}$ It has the potential to increase unprotected sex, poor medication adherence and biological susceptibility to infections; all of which may increase HIV acquisition and transmission. ${ }^{[12]}$

A systematic review concluded that the risk of active TB is greatly increased in people who drink $>40 \mathrm{~g}$ of alcohol per day and/or who have an alcohol use disorder (AUD). This is partly associated with social mixing patterns among those who drink, as well as the influence of alcohol on the immune system. ${ }^{[13]}$ These findings are supported by a more recent review, which noted that the interruption of treatment among HIV and TB patients was significantly higher among those with alcohol dependence as a result of changes in the pharmacokinetics of drugs used in the treatment of HIV and TB with alcohol and the pharmacological interactions that arise because of 
treatment of these chronic illnesses. ${ }^{[14]}$ In the second National Burden of Disease Study, mortality trends from 1997 to 2012 show that, aside from the disease burden associated with high incidence rates of HIV and TB, non-communicable diseases are among the primary causes of death, accounting for $39 \%$ of total deaths in SA. ${ }^{[15]}$ While the overall mortality rate has declined, a greater burden of disease is noted for hypertensive heart disease and diabetes as leading causes of death, especially in the black African population. ${ }^{[15]}$

The associations between alcohol and chronic illnesses are complex. For example, a dual relationship exists for type 2 diabetes and alcohol consumption, where a low risk pattern of drinking may be beneficial, while heavy drinking is detrimental to the diabetic individual's health. ${ }^{[16]}$ Similarly, hypertension is associated with high alcohol consumption, both epidemiological and clinically, but the mechanisms through which alcohol elevates blood pressure are poorly understood. ${ }^{[17]}$

Alcohol consumption patterns are modifiable and a significant body of evidence demonstrates the effectiveness of brief alcohol intervention in primary care settings. ${ }^{[18-25]}$ The SA national Department of Health (DoH) plans to reduce per capita alcohol intake by $20 \%$ by $2020 ;{ }^{[26]}$ however, access to services is hindered by low levels of identification of AUD, ${ }^{[27]}$ an overemphasis on alcohol dependence at specialist clinics and by issues of affordability and the location of such services. ${ }^{[28,29]}$

\section{Objective}

In the context of the high burden of care associated with chronic illnesses (HIV, TB, diabetes and hypertension) and given the high disease burden associated with alcohol use, this article describes the characteristics and correlates of AUDs among chronic care patients who attend primary care clinics in the North West Province of SA. It is especially important to understand patterns of alcohol consumption among chronic care patients in such facilities, given that they constitute the primary facility for healthcare in SA. As part of a larger project to establish the treatment gap for common mental disorders in SA, the focus on rural provinces would help fill the gap regarding the prevalence and treatment of depression and AUD, specifically in these contexts. A secondary goal was to investigate whether patients with these conditions with drinking problems were coming to the clinic for help to address such problems or would be willing to speak to a health worker about alcohol-related problems and to explore their perceptions and attitudes to treatment for AUDs. We reflect on whether the general pattern of alcohol use in SA applies to chronic care patients.

\section{Methods \\ Setting}

The study forms part of the larger work of the PRogramme for Improving Mental health carE (PRIME) in SA, ${ }^{[30]}$ which seeks to integrate and deliver care for AUDs, depression and psychosis in routine primary healthcare. The participants in this study were recruited from three primary healthcare clinics in the Matlosana Subdistrict of the Dr Kenneth Kaunda District in the North West Province, SA between February and April 2014. The three clinics are the early implementation sites for a national $\mathrm{DoH}$ model for integrated chronic disease management, which adopts the collaborative chronic care model ${ }^{[26]}$ and services all chronic care patients at a single service point. ${ }^{[31]}$

\section{Study procedures}

Patients attending the chronic care clinics were recruited from the consultation waiting rooms before their consultation with a clinician. A field worker addressed patients in the general waiting area, stating that '... we are collaborating with the Department of Health to improve health care and conducting a study to provide information about how health services can be improved'. No further study details were provided at this stage. Individuals who showed interest were directed to a research assistant in a private consultation room, where the survey was explained, indicating that it focused on the common mental disorders of depression and AUDs. A consent form was provided in the patient's preferred language. Of those who volunteered, there were no refusals. The research assistants who were recruited from the local communities had completed secondary school, were fluent in seTswana and English, and were trained in administering the Alcohol Use Disorders Identification Test (AUDIT) by a clinical psychologist. The research assistant assessed the patients for inclusion criteria, which were: age $\geq 18$ years, clinic attendance for routine chronic disease services (e.g. HIV, hypertension, diabetes) and ability to comprehend and complete study components in seTswana or English. Exclusion criteria included incapacity to provide informed consent (e.g. $<18$ years of age, presence of severe intellectual disability, intoxication, currently experiencing an acute medical issue, or in treatment for major depression). Eligible patients provided written informed consent to participate in the study and to provide permission for a research clinician to review their clinical notes. Patients with low levels of literacy could sign the informed consent form with an ' $\mathrm{X}$ ' after discussing the study with a study supervisor, and having the consent form read out to them in their preferred language.

Data were collected through the use of a structured questionnaire programmed into an electronic device. Aside from sociodemographic information, the questionnaire was divided into three parts: preconsultation screening, post-consultation exit interviews and clinical notes data extraction. The screening interview was conducted immediately before the clinical consultation, the exit interview immediately afterwards, and the data extraction occurred $\sim 1$ month later. The exit interview and data extraction were only conducted for participants who screened positive for AUDs or for depression, and for a randomly selected $10 \%$ subsample of those who screened negative, to enable comparison of those who screened negative with those who screened positive. The random selection procedure was programmed into the data collection device, and a prompt notified the research assistant to complete the latter two parts of the questionnaire.

\section{Measures}

The preconsultation survey tool comprised sections about demographic characteristics, economic status, screening for depression, screening for AUD, suicidality, chronic condition diagnoses and disability. The study was terminated for most of the participants who screened negative for both depression and AUD. Participants who screened positive for depression or for AUDs were requested to return for a post-consultation exit interview, which consisted of a short series of questions with regard to the participant's visit with the health worker, including the provision of diagnoses, advice, counselling, prescriptions or referrals.

The AUDIT was used to assess for AUD in primary healthcare participants. It comprises 10 items that cover three conceptual dimensions of alcohol consumption that reflect dependence symptoms and alcohol-related consequences, scored from 0 (never occurs) to 4 (daily) over the past 12 months. ${ }^{[32]}$ The AUDIT has been developed and validated by the $\mathrm{WHO}^{[33]}$ as well as in various community and primary healthcare contexts in SA and southern Africa. ${ }^{[34]}$ For this analysis, an AUDIT score of 0 corresponded to abstinence, those who 
scored $\geq 1$ were alcohol consumers, and those who scored $\geq 8$ were screen positive for AUDs. Among those with AUDs, scores of 8 - 15 were consistent with hazardous drinking behaviours, 16 - 19 with harmful drinking (ICD-10, F10.1), and $\geq 20$ with dependent drinking (ICD-10, F10.2). The Cronbach $\alpha$ for this sample was 0.88 .

Depression in this sample was measured using the Patient Health Questionnaire-9 (PHQ-9) ${ }^{[35]}$ for which the Cronbach $\alpha$ was 0.78 . All patients who responded positively to suicidal ideation in the last 2 weeks were asked follow-up questions on their suicide plan and history that were programmed into the questionnaire. The follow-up questions were adapted from the WHO World Mental Health Composite International Diagnostic Interview (WHO WMHCIDI). ${ }^{[36]}$ The device then prompted the interviewer to prepare a suicide-prevention referral form to refer the patient to the consulting professional nurse or doctor, as a positive score on the suicidal ideation item had no clinical utility for predicting suicide. ${ }^{[37]}$ The number of respondents who indicated 'yes' to thoughts about taking their own life in the past 12 months was reflected as a percentage. Severity of disability was measured using the 12-item WHO Disability Assessment Schedule (WHODAS II). ${ }^{[38]}$ The WHODAS measures level of functioning across six domains in life, which include: cognition, mobility, self-care, getting along (interpersonal), life activities (day-to-day) and participation (social dimension). Each dimension is scored as 'none' (1), 'mild' (2), 'moderate' (3), 'severe' (4) and 'extreme' (5) and summed where 0 equals no disability and 100 equals full disability. ${ }^{[37]}$

\section{Analysis}

Age was treated as a continuous variable and educational attainment was categorised into standard educational equivalents (none, primary, secondary and tertiary). Marital status was also classified using standard descriptors (single, partnered, widowed, and separated/ divorced). An economic status index was created by taking the sum of factor loading weights of the first factor of a principal components analysis of four assets (i.e. mobile phone, television, radio, refrigerator) and dummy-coded household characteristics (e.g. electricity, indoor toilet, roof material, cooking fuel). ${ }^{[39]}$ The distribution of economic status scores is normal, with an approximate mean of 0 and standard deviation (SD) of 1 ; participants with scores $>0$ were relatively wealthier than the sample, and those with scores $<0$ were relatively less wealthy.

We first described the sociodemographic and clinical characteristics of the sample and then within each stratum reported the proportion of participants who drink alcohol. ${ }^{[33,40]}$ Secondly, we reported the proportion of patients who have AUDIT scores consistent with abstinence, and with hazardous, harmful or dependent alcohol consumption, stratified by sex and then for the subset of recent drinkers. Logistic regression was then used to identify the demographic and clinical correlates of alcohol consumption (yes/no) in the past 12 months. The results from logistic regression were interpreted as the relative difference in odds of having consumed alcohol for each unit increase of the independent variable. Thirdly, among those participants who had consumed alcohol in the past 12 months, we used zero-truncated negative binomial regression to identify the demographic and clinical correlates of AUDIT scores. We used negative binomial regression rather than linear regression because of the skewed distribution of the AUDIT scores. The exponentiated coefficients from negative binomial regression were interpreted as the relative difference in AUDIT score for each unit increase of the independent variable. Fourthly, we estimated the proportion of participants with an AUDIT score $\geq 8$ and who reported that they were at the clinic for help with alcohol. Finally, we tabulated the stigmatis- ing beliefs and help-seeking behaviours exhibited among those with harmful alcohol consumption.

\section{Ethical approval}

Ethical approval for the study was obtained from the University of KwaZulu-Natal (SA) Biomedical Research Ethics Committee (BE400/13), the University of Cape Town (SA) Faculty of Health Sciences Human Research Ethics Committee (412/2011) and the WHO (Geneva, Switzerland) Research Ethics Review Committee (RPC497).

\section{Results}

Using the convenience sampling approach described earlier, 1322 eligible patients were enrolled into the study. The sample characteristics are shown in Table 1.

Of the total sample of 1322 participants, $75 \%$ (994) were female. It is not unusual to find a higher ratio of female to male patients attending primary care clinics. For example, $73 \%$ of the 4393 participants in a multimorbidity study of non-communicable diseases in the

Table 1. Sociodemographic and clinical characteristics for participants of the PRIME Facility Detection Survey, Matlosana Subdistrict, Dr Kenneth Kaunda District, SA, 2014

\begin{tabular}{|c|c|}
\hline \multicolumn{2}{|l|}{ Sociodemographic characteristics } \\
\hline Age (years), mean (SD) & $46.8(13.2)$ \\
\hline \multicolumn{2}{|l|}{ Sex, $n(\%)$} \\
\hline Female & $994(75.2)$ \\
\hline Male & $328(24.8)$ \\
\hline Education (years), mean (SD) & $7.8(3.5)$ \\
\hline \multicolumn{2}{|l|}{ Marital status, $n(\%)$} \\
\hline Single & $410(31.0)$ \\
\hline Partnered & $623(47.1)$ \\
\hline Widowed & $194(14.7)$ \\
\hline Separated/divorced & $95(7.2)$ \\
\hline \multicolumn{2}{|l|}{ Employment status, $n(\%)$} \\
\hline Unpaid voluntary & $16(1.2)$ \\
\hline Unemployed & $524(39.6)$ \\
\hline Student & $14(1.1)$ \\
\hline Retired & $257(19.4)$ \\
\hline Employed full-time & $105(7.9)$ \\
\hline Employed part-time & $170(12.9)$ \\
\hline Piece jobs & $233(17.6)$ \\
\hline Other & $3(0.2)$ \\
\hline \multicolumn{2}{|l|}{ Health-related characteristics } \\
\hline $\mathrm{HIV}, n(\%)$ & $785(47.3)$ \\
\hline Hypertension, $n(\%)$ & $679(40.9)$ \\
\hline Diabetes, $n(\%)$ & $124(7.5)$ \\
\hline Tuberculosis, $n(\%)$ & $73(4.4)$ \\
\hline PHQ-9 score, mean (SD) & $3.9(3.9)$ \\
\hline Suicidal ideation, $n(\%)$ & $106(8.0)$ \\
\hline WHODAS score, mean (SD) & $17.2(6.3)$ \\
\hline
\end{tabular}


Table 2. Alcohol consumption behaviour among chronic care patients by gender and chronic illness, Matlosana Subdistrict, Dr Kenneth Kaunda District, SA, 2014

\begin{tabular}{|c|c|c|c|c|c|c|c|}
\hline $\begin{array}{l}\text { Alcohol consump- } \\
\text { tion behaviour }\end{array}$ & $\begin{array}{l}\text { All participants } \\
(N=1322) \\
n(\%)^{*}\end{array}$ & $\begin{array}{l}\text { Men } \\
(N=328), n(\%)\end{array}$ & $\begin{array}{l}\text { Women } \\
(N=994), n(\%)\end{array}$ & $\begin{array}{l}\text { HIV patients } \\
(N=785), n(\%)\end{array}$ & $\begin{array}{l}\text { Hypertension } \\
\text { patients } \\
(N=679), n(\%)\end{array}$ & $\begin{array}{l}\text { Diabetes } \\
\text { patients } \\
(N=124), n(\%)\end{array}$ & $\begin{array}{l}\text { Tuberculosis } \\
\text { patients } \\
(N=73), n(\%)\end{array}$ \\
\hline Alcohol abstinent & $724(54.8)$ & $126(38.4)$ & $598(60.2)$ & $396(50.4)$ & $411(60.5)$ & $81(65.3)$ & $34(46.6)$ \\
\hline Non-AUD drinker & $422(31.9)$ & $123(37.5)$ & $299(30.1)$ & $257(32.7)$ & $209(30.8)$ & $37(29.8)$ & $22(30.1)$ \\
\hline Hazardous drinking & $133(10.1)$ & $52(15.9)$ & $81(8.1)$ & $101(12.9)$ & $44(6.5)$ & $6(4.8)$ & $6(8.2)$ \\
\hline Harmful drinking & $22(1.7)$ & $13(4.0)$ & $9(0.9)$ & $15(1.9)$ & $7(1.0)$ & 0 & $4(5.5)$ \\
\hline Dependent drinking & $21(1.6)$ & $14(4.3)$ & $7(0.7)$ & $16(2.0)$ & $8(1.2)$ & 0 & $7(9.6)$ \\
\hline
\end{tabular}

Western Cape Province were female. ${ }^{[41]}$ The mean age of our sample was 47 years, with the majority having attended secondary school (74\%). Just under half $(47 \%)$ of the sample reported their marital status as being with a partner. Only $8 \%$ of the sample reported full-time employment, and a further $30 \%$ part-time employment, with $41 \%$ reporting being unemployed. Forty-six percent were receiving either pensions or grants, while $41 \%$ reported earning a salary or a wage.

Self-report indicated that $\sim 1$ in $5(21 \%)$ of the respondents or their family had gone hungry owing to lack of food in the month prior to the interview. Most of the patients at the clinic were there to receive care for HIV (47\%) and/or hypertension (41\%).

Of the 1322 patients screened, 598 (45\%) of the sample reported alcohol use (Table 2). The abstinence proportion was $60 \%$ among women and 38\% among men. Among drinkers, 22\% had AUDIT scores consistent with hazardous drinking patterns, $3.7 \%$ with harmful drinking and $3.5 \%$ with dependent drinking. The use of alcohol in relation to sex and chronic condition revealed considerable variation in drinking patterns. Similarly, $4.3 \%$ of men had dependent alcohol use, in comparison to $0.7 \%$ of women. TB patients had the lowest abstinence proportion (47\%) and highest proportion (10\%) with dependent drinking, while diabetes patients had the highest abstinence proportion (65\%), with no diabetes patients reporting dependent behaviours. The alcohol consumption patterns for HIV and hypertension patients fell between the TB and diabetes patients.

Table 3 shows relative ratios for drinking alcohol in the full sample, and the relative AUDIT scores among the 598 participants who consumed alcohol. For every 10 -year increase in age, the probability of being a drinker decreased by $13 \%$. Men were $55 \%$ more likely than women to report drinking. Participants who were widowed or retired were substantially less likely to report drinking. For each unit increase in the economic asset score, the ratio of drinking was $6 \%$ lower.

HIV patients were $27 \%$ more likely to be drinkers than non-HIV patients, and diabetes patients were $25 \%$ less likely to be drinkers than non-diabetes patients.

Among drinkers, each decade increase in age was associated with an $18 \%$ lower AUDIT score. Males had AUDIT scores that were $63 \%$ higher than those for women. Education level was not associated with more or less alcohol use, nor did it differentiate on the basis of AUDIT score. Partnered and retired participants had relatively lower AUDIT scores. TB patients had AUDIT scores $88 \%$ higher than non-TB patients, and diabetes patients had scores $38 \%$ lower than non-diabetes patients. For each unit increase in the PHQ-9 and WHODAS scores, there was a $7 \%$ and $3 \%$ increase in AUDIT score, respectively. Those who reported suicidal ideation had $73 \%$ higher AUDIT scores.
While a sizeable proportion (63\%) of the participants who drink and who were polled before exiting the clinic would find talking to a healthcare worker about drinking problems helpful, only $28 \%(n=92)$ indicated that they would talk to a health worker specifically about their drinking problems. However, only $19 \%(n=8)$ of individuals who screened positive for AUDs had come to the clinic for help with alcohol problems. The perceptions of and attitudes to treatment for AUDs are shown in Table 4. Poor understanding and/or low levels of literacy (9\%), stigma $(6 \%)$ and accessibility to services $(5 \%)$ were primary concerns.

\section{Discussion}

Nearly half (45\%) of chronic care patients in this subdistrict reported alcohol use, and of those who drank, $3 \%$ had an AUDIT score consistent with an AUD. The overall percentage of those who drink alcohol $(45 \%)$ is in keeping with earlier findings ${ }^{[4]}$ and the trends towards more hazardous and harmful drinking patterns persist among men, with almost a quarter of the men $(24.2 \%)$ reporting consuming alcohol at risky levels. Men are much more likely to drink and have AUDs. It has generally been found that women who drink tend also to drink quite a lot. ${ }^{[42]}$ In the current survey, the absolute number of women who drank (non-AUD) (30\%) exceeded that of men. As pointed out above, public primary care clinics in SA generally have higher female than male attendance, mainly because the type of available services is largely orientated to women and children.

The heavy use of alcohol among those with TB (23.3\%) echoes the findings of others, but also points to the potential for compromising treatment efficacy for the chronic condition. ${ }^{[4,14]}$ The burden associated with heavy alcohol use among those with HIV (17\%) is known to affect adherence, aside from lowering the CD4 count among those not on antiretroviral medication. ${ }^{[11]}$ The increased likelihood of drinking at risky levels among those who drink for both HIV and TB is starkly demonstrated in the regression results and confirms the deleterious effects of alcohol use in these groups, as the overall volume of alcohol consumed is deemed to be responsible for the effect of alcohol on the burden of chronic diseases. ${ }^{[43]}$ The lower AUDIT scores among diabetic and hypertensive patients are encouraging and may suggest better management of these conditions at a clinic level. Nevertheless, the known comorbidities of these conditions with cardiovascular and circulatory diseases as well as stroke cannot be underestimated in men and women. ${ }^{[43]}$

The lower levels of alcohol consumption among those living in a partnership, and in those who are widowed or retired and the concomitant lower risk associated with increasing age indicate that younger patients who are single are more likely to be heavy consumers of alcohol. In addition to the burden associated with heavy drinking in a younger group of patients, risk for this group is 
Table 3. Sociodemographic and health-related correlates of alcohol consumption and of AUDIT scores among chronic care patients, Matlosana Subdistrict, Dr Kenneth Kaunda District, SA, 2014

\begin{tabular}{|c|c|c|}
\hline Characteristics & $\begin{array}{l}\text { Among all participants }(N=1322) \text {, relative ratio } \\
\text { for alcohol consumption }{ }^{\dagger}(95 \% \mathrm{CI})\end{array}$ & $\begin{array}{l}\text { Among participants who consume alcohol } \\
(N=598) \text {, relative AUDIT score }(95 \% \mathrm{CI})\end{array}$ \\
\hline \multicolumn{3}{|c|}{ Sociodemographic characteristics } \\
\hline Age (per 10 years) & $0.87^{\star \star \star}(0.83-0.91)$ & $0.82^{\star \star \star}(0.75-0.88)$ \\
\hline \multicolumn{3}{|l|}{ Sex } \\
\hline Female & Ref. & Ref. \\
\hline Male & $1.55^{* *}(1.38-1.74)$ & $1.63^{* *}(1.36-1.96)$ \\
\hline Education (years) & $1.00(0.98-1.02)$ & $1.02(0.99-1.05)$ \\
\hline \multicolumn{3}{|l|}{ Marital status } \\
\hline Single & Ref. & Ref. \\
\hline Partnered & $1.10(0.97-1.26)$ & $0.74^{* *}(0.60-0.91)$ \\
\hline Widowed & $0.75^{\star \star}(0.60-0.93)$ & $0.84(0.58-1.21)$ \\
\hline Separated/divorced & $0.96(0.75-1.24)$ & $1.04(0.71-1.52)$ \\
\hline \multicolumn{3}{|l|}{ Employment status } \\
\hline Unemployed & Ref. & Ref. \\
\hline Employed & $1.09(0.96-1.24)$ & $1.10(0.91-1.33)$ \\
\hline Retired & $0.77^{\star *}(0.64-0.93)$ & $0.53^{* * *}(0.37-0.75)$ \\
\hline Economic index score & $0.94^{\star}(0.88-0.99)$ & $0.93(0.82-1.04)$ \\
\hline \multicolumn{3}{|c|}{ Health-related characteristics } \\
\hline \multicolumn{3}{|l|}{ HIV } \\
\hline No & Ref. & Ref. \\
\hline Yes & $1.27^{* * *}(1.12-1.44)$ & $1.41^{* * *}(1.15-1.74)$ \\
\hline \multicolumn{3}{|l|}{ Hypertension } \\
\hline No & Ref. & Ref. \\
\hline Yes & $0.77^{\star * \star}(0.68-0.87)$ & $0.71^{\star * *}(0.59-0.87)$ \\
\hline \multicolumn{3}{|l|}{ Diabetes } \\
\hline No & Ref. & Ref. \\
\hline Yes & $0.75^{\star}(0.58-0.96)$ & $0.62^{\star \star}(0.44-0.88)$ \\
\hline \multicolumn{3}{|l|}{ Tuberculosis } \\
\hline No & Ref. & Ref. \\
\hline Yes & $1.19(0.95-1.49)$ & $1.88^{* * *}(1.32-2.68)$ \\
\hline PHQ-9 score & $1.02^{* * *}(1.00-1.03)$ & $1.07^{\star * *}(1.05-1.09)$ \\
\hline \multicolumn{3}{|l|}{ Suicidal ideation } \\
\hline No & Ref. & Ref. \\
\hline Yes & $1.18(0.98-1.43)$ & $1.73^{* * *}(1.28-2.35)$ \\
\hline WHODAS score & $1.01(0.99-1.03)$ & $1.03^{* *}(1.01-1.06) \S$ \\
\hline
\end{tabular}

further complicated by the positive association between depression scores, suicidal ideation and disability, thereby considerably adding to the risk of ill health in this group. Screening for risky patterns of drinking in younger patients who present with various health issues may provide a partial answer to influencing drinking behaviour in these patients. Programmes to address underlying depression may also be considered to help to reduce heavy drinking.

The unmet need of those with alcohol-related problems is exacerbated by the underidentification and failure to treat alcohol use as a comorbid illness, with only $37 \%$ of patients with AUDs indicating that they would discuss alcohol-related issues with professional staff. While this may well be related to perceptions of stigma or reduced opportunities for receiving treatment, which are not unique to this setting, ${ }^{[44]}$ it also suggests a poor understanding of the availability of treatment and low levels of literacy.

Primary care settings would benefit from devoting increased resources to training in identifying AUDs, as the evidence shows that more than half of the the population consider discussion of emotional 
Table 4. Perceptions and attitudes to treatment for AUD among chronic care patients with harmful or dependent drinking $(N=43)$, Matlosana Subdistrict, Dr Kenneth Kaunda District, SA, 2014

\begin{tabular}{ll}
\hline Characteristics & $\boldsymbol{n}(\%)$ \\
\hline Poor understanding/low health literacy & \\
Unsure of where to seek professional help & $28(65.1)$ \\
Thought the problem would get better by itself & $28(65.1)$ \\
Wanted to handle problem on my own & $27(62.8)$ \\
Did not think the problem could be treated & $16(37.2)$ \\
Concerned about effects of the treatment itself & $14(32.6)$ \\
Problem didn't bother me too much & $9(20.9)$
\end{tabular}

Stigma/reduced opportunities

Concerned about what others might think if sought help 18 (41.9)

People would think less of me for seeking

professional help

People might treat me differently if aware I was

seeking professional help

Concerned would harm chances of finding or

keeping work

Family members would disapprove

Felt ashamed/embarrassed to seek professional help

Harm own or family members' chances of marriage

$8(18.6)$

Accessibility issues/concerns

Transport problems prevented getting help

Scared of being hospitalised against my will

Getting professional help would take too much time or be inconvenient

Childcare/scheduling difficulties prevented getting help

Too far to travel to clinic/hospital

Unsatisfactory services

Not satisfied with available services

Received treatment before and it did not work

Cost issues

Concerned about cost of professional help

Cannot afford the cost of travel

AUD $=$ alcohol use disorder.

problems to be helpful. The manner in which harmful and hazardous alcohol manifests also suggests the need for greater efforts at increasing public health information about hazardous and harmful patterns of alcohol consumption. Sensitivity in how to approach the issue of AUD in chronic care patients needs to be included in the training of primary healthcare providers, given the possibility of stigmatising attitudes towards patients with AUD.

The weaknesses of this study include that it was cross-sectional and the direction of influence between alcohol, depression and various other chronic illnesses cannot be determined. Nevertheless, recruitment of participants without reference to either mental health or alcohol use may have helped mitigate sample selection bias. Given that this was a convenience sample, the ability to generalise beyond the population of chronic care facility attendees in the North West Province may be affected. However, the study sample size, together with the low identification of AUDs and stigma that are common across SA, makes this less likely. Further, there may be an underrepresentation of those who consume alcohol and downward bias in AUDIT scores given the associated stigma and the negative attitudes in general from the public and healthcare staff.

\section{Conclusion}

There is an urgent need to address the absence of appropriate mechanisms and processes to deal with patterns of alcohol consumption among chronic care patients in order to enhance treatment efficacy. There are effective treatments for those who demonstrate risky patterns of alcohol consumption in public health services. Multifaceted strategies that combine professional approaches with patient-orientated approaches and that use mid-level health professionals appear to work best. ${ }^{[45]}$ Instituting appropriate screening measures and referral to treatment would appear to be a first step in mitigating the devastating effects of risky alcohol use among chronic care patients. This is especially so among HIV and TB patients rather than those with hypertension or diabetes. Inadequate attention to these comorbid issues will simply exacerbate the problems associated with chronic care. Future research should focus on developing and evaluating appropriate brief interventions for HIV and TB patients to be delivered at a primary care level. Finally, harm reduction approaches to dealing with alcohol are as much a concern for women as they are for men, suggesting that a strategy that targets both groups is important in public health settings.

Acknowledgements. Our grateful thanks to the patients for their enduring patience and participation in the various phases of the assessments. We also wish to thank the data collection team, Palesa Mothibedi, Primrose Mpahane, Rothea Kruger, Emily Lesekele, Mirriam Maphai, Sammy Ostheleng and their respective teams. This study is an output of the PRogramme for Improving Mental health carE (PRIME).

Author contributions. AB, SDR and IP were involved in the conceptualisation, analysis, drafting and final versions of the manuscript. OS and TK were involved in drafting and editing of the final manuscript. All the authors reviewed the manuscript and approved submission.

Funding. The material has been funded by UK aid and the UK government; however, the views expressed do not necessarily reflect the UK government's official policies.

Conflicts of interest. None.

1. Rehm J, Room R, Monteiro M, et al. Alcohol as a risk factor for global burden of disease. Eur Addict Res 2003;9(4):157-164. http://dx.doi.org/10.1159/000072222.

2. World Health Organization. Global Status Report on Alcohol and Health - 2014. Geneva: WHO, 2014. Schneider M, Norman R, Parry C, Bradshaw D, Pluddemann A. Estimating the burden of disease attributable to alcohol use in South Africa in 2000. S Afr Med J 2007;97(82):664-672

4. Rehm J, Parry C. Alcohol consumption and infectious diseases in South Africa. Lancet 2009;374(9707):2053. http://dx.doi.org/10.1016/s0140-6736(09)62150-4

Clausen T, Rossow I, Naidoo N, Kowal P. Diverse alcohol drinking patterns in 20 African countries. Addiction 2009;104(7):1147-1154. http://dx.doi.org/10.1111/j.1360-0443.2009.02559.x

6. Van Heerden MS, Grimsrud AT, Seedat S, Myer L, Williams DR, Stein DJ. Patterns of substance use in South Africa: Results from the South African Stress and Health study. S Afr Med J 2009;99(5):358-366. National Departinent of Health. South African Demographic and Health Survey 2003. Pretoria: NDoH, 2007.

Shisana O, Rehle T, Simbayi LC, et al. South African National HIV Prevalence, HIV incidence, Behaviour and Communication Survey, 2005. Cape Town: Human Sciences Research Council, 2005.

9. Parry C, Ferreira-Borges C, Poznyak V, Lönnroth K, Rehm J. The international study on alcohol and infectious diseases: Three priorities for research. Addiction 2013;108(1):1-2. http://dx.doi.org/10.1111/ .1360-0443.2012.04000.

10. Kasprowicz VO, Achkar JM, Wilson D. The tuberculosis and HIV epidemic in South Africa and the KwaZulu-Natal Research Institute for Tuberculosis and HIV. J Infect Dis 2011;204(Suppl 4):S1099-S1101. http://dx.doi.org/10.1093/infdis/jir414

11. Samet JH, Cheng DM, Libman H, Nunes DP, Alperen JK, Saitz R. Alcohol consumption and HIV disease progression. J Acquir Immune Defic Syndr 2007;46(2):194-199. http://dx.doi.org/10.1097/ QAI.0b013e318142aabb

12. Hahn JA, Woolf-King SE, Muyindike W. Adding fuel to the fire: Alcohol's effect on the HIV epidemic in sub-Saharan Africa. Curr HIV/AIDS Rep 2011;8(3):172-180. http://dx.doi.org/10.1007/s11904-0100060-6 
13. Lönnroth K, Williams BG, Stadlin S, Jaramillo E, Dye C. Alcohol use as a risk factor for tuberculosis a systematic review. BMC Public Health 2008:8(1):1-12. http://dx.doi.org/10.1186/1471-2458-8-289 4. Rehm J, Samokhvalov AV, Neuman MG, et al. The association between alcohol use, alcohol use disorders and tuberculosis (TB). A systematic review. BMC Public Health 2009;9(1):450. http://dx.doi.
dite disorders and tuberculosis (TB)
org/10.1186/1471-2458-9-450

org/10.1186/1471-2458-9-450
15. Pillay-van Wyk V, Msemburi W, Laubscher R, et al. Mortality trends and differentials in South Africa from 1997 to 2012: Second National Burden of Disease Study. Lancet Glob Health 2016;4(9):e642-e653. http://dx.doi.org/10.1016/\$2214-109X(16)30113-9

16. Baliunas DO, Taylor BJ, Irving H, et al. Alcohol as a risk factor for type 2 diabetes: A systematic review and meta-analysis. Diabetes Care 2009;32(11):2123-2132. http://dx.doi.org/10.2337/dc09-0227

17. Husain K, Ansari RA, Ferder L. Alcohol-induced hypertension: Mechanism and prevention. World J Cardiol 2014;6(5):245-252. http://dx.doi.org/10.4330/wjc.v6.15.245

18. Agerwala SM, McCance-Katz EF. Integrating screening, brief intervention, and referral to treatment (SBIRT) into clinical practice settings: A brief review. J Psychoactive Drugs 2012;44(4):307-317. http:/ dx.doi.org/10.1080/02791072.2012.720169

19. Babor TF, Higgins-Biddle JC, Dauser D, Burleson JA, Zarkin GA, Bray J. Brief interventions for at-risk drinking: Patient outcomes and cost-effectiveness in managed care organizations. Alcohol Alcohol 2006;41(6):624-631. http://dx.doi.org/10.1093/alcalc/agl078

20. Huis in't Veld D, Skaal L, Peltzer K, et al. The efficacy of a brief intervention to reduce alcohol misuse in patients with HIV in South Africa: Study protocol for a randomized controlled trial. Trials 2012;13(1):190. http://dx.doi.org/10.1186/1745-6215-13-190

21. Kaner E, Bland M, Cassidy P, et al. Effectiveness of screening and brief alcohol intervention in primary care (SIPS trial): Pragmatic cluster randomised controlled trial. BMJ 2013;346(2):e8501. http://dx.do org/10.1002/14651858.CD004148.pub3

22. Kaner EF, Dickinson HO, Beyer F, et al. The effectiveness of brief alcohol interventions in primary care settings: A systematic review. Drug Alcohol Rev 2009;28(3):301-323. http://dx.doi.org/10.1111/j.14653362.2009.00071.x

23. Kaner EF, Dickinson HO, Beyer FR, et al. Effectiveness of brief alcohol interventions in primary care populations. Cochrane Database Syst Rev 2007;2:CD004148. http://dx.doi.org/10.1002/14651858. CD004148.pub3

24. Peltzer K, Naidoo P, Louw J, et al. Screening and brief interventions for hazardous and harmful alcohol use among patients with active tuberculosis attending primary public care clinics in South Africa: Results from a cluster randomized controlled trial. BMC Public Health 2013;13(1):699. http://dx.doi. Results from a cluster randomize
org/10.1186/1471-2458-11-394

25. Sorsdahl K, Myers B, Ward C, et al. Screening and brief interventions for substance use in emergency departments in the Western Cape province of South Africa: Views of health care professionals. Int I Inj Contr Saf Promot 2014;21(3):236-243. http://dx.doi.org/10.1080/17457300.2013.811267

26. National Department of Health. Strategic Plan for the Prevention and Control of Non-Communicable Diseases 2013 - 2017. Pretoria: NDoH, 2013.

27. Petersen I, Fairall L, Bhana A, et al. Integrating mental health into chronic care in South Africa: The development of a district mental healthcare plan. Br J Psychiatry 2015;208(Suppl 56):s29-s39. http:// dx.doi.org/10.1192/bjp.bp.114.153726

28. Myers B, Sorsdahl K. Addressing substance use within primary health care settings in South Africa: Opportunities and challenges. Addicta Turk J Addict 2014;1(2):80-94. https://dx.doi.org/10.15805/ addicta.2014.1.2.023

29. Bhana A. A misplaced focus: Harmful drinking patterns in South Africa. Subst Use Misuse 2015:50(89):1089-1091. http://dx.doi.org/10.3109/10826084.2015.1007658
30. Lund C, Tomlinson M, de Silva M, et al. PRIME: A programme to reduce the treatment gap for mental disorders in five low- and middle-income countries. PLoS Med 2012;9(12):e1001359. http://dx.doi org/10.1371/journal.pmed.1001359

31. Mahomed OH, Asmall S, Freeman M. An integrated chronic disease management model: A diagonal approach to health system strengthening in South Africa. J Health Care Poor Underserved diagonal approach to health system strengthening in South Africa.

32. Babor TF, Higgins-Biddle JC. Brief Intervention For Hazardous and Harmful Drinking. A Manual for Use in Primary Care. Geneva: World Health Organization, 2001. http://apps.who.int/iris/bitstream/10665/67210/1/ WHO_MSD_MSB_01.6b.pdf (accessed 1 June 2017).

33. Saunders JB, Aasland OG, Babor TF, de la Fuente JR, Grant M. Development of the Alcohol Use Disorders Identification Test (AUDIT): WHO Collaborative Project on Early Detection of Person with Harmful Alcohol Consumption - II. Addiction 1993;88(6):791-804.

34. Myer L, Smit J, Roux LL, Parker S, Stein DJ, Seedat S. Common mental disorders among HIV-infected individuals in South Africa: Prevalence, predictors, and validation of brief psychiatric rating scales AIDS Patient Care STDS 2008;22(2):147-158. http://dx.doi.org/10.1089/apc.2007.0102

35. Bhana A, Rathod SD, Selohilwe O, Kathree T, Petersen I. The validity of the Patient Healt Questionnaire for screening depression in chronic care patients in primary health care in South Africa. BMC Psychiatry 2015;15(1):118. http://dx.doi.org/10.1186/s12888-015-0503-0

36. World Health Organization. The World Health Organization World Mental Health Composite Internationa Diagnostic Interview (WHO WMH-CIDI) 2016. http://www.hcp.med.harvard.edu/wmhcidi/ (accessed 1 June 2017).

37. Louzon SA, Bossarte R, McCarthy JF, Katz IR. Does suicidal ideation as measured by the PHQ-9 predict suicide among VA patients? Psychiatr Serv 2016;67(5):517-522. http://dx.doi.org/10.1176/appi. ps. 201500149

38. World Health Organization. WHODAS II Disability Assessment Schedule Training Manual: A Guide to Administration. Geneva: WHO, 2004. http://www.whoint/icidh/whodas/training man.pdf (accessed 1 June 2017)

39. Vyas S, Kumaranayake L Constructing socio-economic status indices: How to use princip components analysis. Health Policy Plan 2006-21(6):459-468. http://dx.doi.org/10.1093/heapol/czlo29 Babor TF, Higgins-Biddle IC Saunders JB, Monteiro MG. AUDIT. The Alcohol Use Disorders Identification Test. Guidelines for Use in Primary Care Geneva: World Health Organization, 2001.

Folb N Timmer. $V$, Levitt NS, et al Multimobidity control and treatment of nzommunicable . Folb N, Timmerman V, Levitt NS, et al. Multimorbidity, control and treatment of noncommunicable diseases among primary healthcare attenders in the Western

42. Parry CD, Pluddemann A, Steyn K, Bradshaw D, Norman R, Laubscher R. Alcohol use in South Africa: Findings from the first Demographic and Health Survey (1998). J Stud Alcohol 2005;66(1):91-97.
Find

43. Shield KD, Parry C, Rehm J. Focus on: Chronic Diseases and Conditions Related to Alcohol Use. Washington, DC: National Institute on Alcohol Abuse and Alcoholism (undated). http://pubs.niaaa. nih.gov/publications/arcr352/155-173.htm (accessed 1 June 2017).

44. Wallhed Finn S, Bakshi AS, Andréasson S. Alcohol consumption, dependence, and treatment barriers: Perceptions among nontreatment seekers with alcohol dependence. Subst Use Misuse 2014;49(6):762 769. http://dx.doi.org/10.3109/10826084.2014.891616

45. Keurhorst M, van de Glind I, Bitarello do Amaral-Sabadini M, et al. Implementation strategies to enhance management of heavy alcohol consumption in primary health care: A meta-analysis Addiction 2015;110(12):1877-1900. http://dx.doi.org/10.1111/add.13088

Accepted 27 February 2017 